\title{
Trade Openness, Economic Size, and Macroeconomic Volatility: Theory and Empirical Evidence
}

\author{
Georgios Karras \\ University of Illinois at Chicago
}

\begin{abstract}
The effects of trade openness on macroeconomic volatility are theoretically ambiguous, so the issue must be resolved empirically. Most of the empirical evidence, however, has been mixed and inconclusive. This paper investigates the question using two data sets: one of 56 countries over 1951-1998, and another of 105 countries over 1960-1997. It is shown that, when their effects are jointly estimated, both economic size and trade openness have a sizable, negative, and generally statistically significant effect on the variability of output, consumption, investment, and the exchange rate. It is also found that depreciation rates are inversely related to both economic size and openness. These effects are robust across the two data sets and three different detrending methods.
\end{abstract}

- JEL classification: E32, F41

- Keywords: Openness, Macroeconomic Volatility, Investment, Consumption

\section{Introduction}

One of the most obvious characteristics of "globalization" has been a remarkably widespread increase in openness to international trade. Naturally, a large (and still rapidly expanding) literature has concentrated on modeling and estimating the economic consequences of trade openness. However, the overwhelming majority of the literature's theoretical and empirical contributions have concentrated on the

*Corresponding address: Georgios Karras, Professor of Economics, Department of Economics, University of Illinois at Chicago, Chicago, IL 60607-7121; e-mail: gkarras@uic.edu. (c)2006-Center for International Economics, Sejong Institution, All Rights Reserved. 
links between trade openness and economic growth, ${ }^{1}$ while the relationship between openness and economic volatility has been, with few exceptions, almost completely neglected.

These exceptions have been very few indeed. On the theoretical front, in particular, there seem to exist no more than a handful of studies that address the issue. The most recent contribution is by Razin, Sadka, and Coury (2002, 2003), who develop a model in which trade openness has the potential to produce boombust cycles of investment, and therefore destabilize the economy. Another study that models the relationship is by Gali and Monacelli (1999) who, using a model of optimal monetary policy, show that an increase in openness should reduce the volatility of the exchange rate, increase the volatility of output, but have an ambiguous effect on the volatility of consumption. Guender (2003) carefully distinguishes between domestic- and CPI-inflation targeting: his model predicts a U-shaped relationship between output variability and openness when domestic inflation is targeted; but when the target is CPI inflation, output variance is strictly increasing with openness. Hau's (2002) theoretical model also predicts an inverse relationship between trade openness and the volatility of the real exchange rate.

The number of empirical contributions has also been surprisingly small and (less surprisingly) generally inconclusive. After a thorough examination of the businesscycle variability of output, consumption, and investment for 130 countries, Razin and Rose (1994) were "unable to find significant correlations between openness and volatility." Karras and Song (1996), on the other hand, argue that trade openness has been positively correlated with output volatility in a sample of 24 OECD countries. Similarly, Kose, Prasad, and Terrones (2003) find that an increase in financial openness is associated with higher relative volatility of consumption, though "only up to a certain threshold." Finally, consistent with his theoretical predictions, Hau (2002) shows that trade openness has been negatively correlated with real-exchange rate volatility in a cross section of 48 countries.

The present paper continues with a brief theoretical section, developing a simple

\footnotetext{
Theoretical models of the effects of openness on growth can be found in Grossman and Helpman (1991), Barro and Sala-i-Martin (1995), and Obstfeld and Rogoff (1996). For empirical evidence, see Edwards (1999), Frankel and Romer (1999), and Irwin and Terviö (2002).

${ }^{2}$ Buch, Döpke, and Pierdzioch (2002) also look at financial openness and conclude that its link with business-cycle volatility is so difficult to establish empirically because it must have changed over time. IMF (2002), on the other hand, after demonstrating that trade openness and financial openness are "highly correlated across both industrial and developing countries" argues that they both reduce macroeconomic instability.
} 
combination of the approaches of Romer (1993) and Obstfeld and Rogoff (1996). The model predicts that the average inflation and depreciation rates are decreasing in the degree of openness, but it also demonstrates that the effects of openness on macroeconomic volatility are theoretically ambiguous. This clearly implies that the issue has to be resolved empirically.

The main goal of the paper, therefore, is to contribute to the empirical side of the question using annual data from the post-war period for a total of 105 developed and developing economies. In particular, two data sets will be used: the first consists of 56 countries with annual observations over 1951-1998, and the second covers 105 countries for the period 1960-1997. The results show that simple bivariate correlations between trade openness and various measures of macroeconomic volatility are positive but fragile, small, and generally statistically insignificant, as found by much of the literature. It is shown, however, that once the effects of economic size have been taken into account, both trade openness and economic size are found to have a sizable, negative, and generally statistically significant effect on macroeconomic volatility, as measured by the business-cycle variability of output, consumption, investment, and the exchange rate. It is also found that depreciation rates are inversely related to both economic size and trade openness. These effects are robust across the two data sets used and three different detrending methods.

The rest of the paper is organized as follows. Section 2 presents the simple theoretical model. Section 3 discusses the sources of the data, defines the variables to be used in the estimation, and describes the three detrending methods. Section 4 presents the empirical results, and section 5 discusses the findings and concludes.

\section{A Simple Theoretical Model}

This section outlines a simple theoretical model to illustrate how trade openness can influence macroeconomic volatility through the conduct of monetary policy. The approach is based on the influential model of monetary policy credibility pioneered by Kydland and Prescott (1977) and Barro and Gordon (1983), and later extended to include open-economy considerations by Rogoff (1985), and Obstfeld and Rogoff (1996), among others.

Following Obstfeld and Rogoff (1996), assume that the government's loss function takes the form:

$$
L=\frac{1}{2} E\left[\alpha(y-\hat{y})^{2}+\pi^{2}\right]
$$


where $y$ is $(\log )$ real GDP, $\hat{y}$ is the government's target for $y, \pi$ is the inflation rate, $E$ denotes the mathematical expectation, and $\alpha$ is positive parameter which captures the importance of the output target relative to inflation (which is assumed to have a target of zero).

Output is given by an expectations-augmented Phillips curve

$$
y=\beta\left(\pi-\pi^{e}\right)+u
$$

where the "natural rate" of output has been normalized to zero (in effect interpreting $y$ as deviations from the trend, or the "cyclical" component of output), $\pi^{e}$ denotes expected inflation, $u \sim$ iid $\left(0, \sigma_{u}{ }^{2}\right)$ is an output shock, and $\beta$ (the slope of the aggregate supply) is a parameter that captures the Phillips curve trade off between inflation and output. ${ }^{3}$

Two implications of the openness of the economy are now considered. First, we are making $\beta$ a decreasing function of openness, in order to incorporate the assumption that "the output-inflation Phillips curve trade-off is worse in an open economy than in a closed economy" (Obstfeld and Rogoff, 1996). The same point has been made in a variety of theoretical approaches, including those of Rogoff (1985), Romer (1993), and Karras (1999). Thus we assume:

$$
\beta=\beta(\text { open })
$$

with $\beta^{\prime} \equiv \partial \beta / \partial$ open $<0$, where the variable open measures the degree of openness of the economy.

Second, and again following Obstfeld and Rogoff (1996), we include a Purchasing Power Parity (PPP) relationship, which implies:

$$
\pi=\Delta e+v=\varepsilon+v
$$

where $e$ is the (log, nominal) exchange rate, $\varepsilon \equiv \Delta e$ is the (nominal) depreciation rate, the error term $v \sim$ iid $\left(0, \sigma_{v}^{2}\right)$ captures deviations from exact PPP, and the foreign price level is assumed to be exogenous (and has been normalized to 1).

The policy goal is to select $\varepsilon$ in order to minimize (1) subject to (2), (3), and (4).

\footnotetext{
${ }^{3}$ Very similar results would be obtained if we used the more recently developed "New Keynesian" monetary policy model of Clarida, Gali, and Gertler (1999). There the loss function is given by $L=\frac{1}{2} E_{t}\left\{\sum_{j=0}^{\infty} \rho^{j}\left[a\left(y_{t+j}-\hat{y}_{t+j}\right)+\pi_{t+j}^{2}\right]\right\}$, where $\rho$ is the discount factor, and aggregate supply is given by a "New Keynesian" expectations-augmented Phillips curve, $\pi_{t}=\lambda y_{t}+E_{t} \pi_{t+1}+w_{t}$, with $\lambda>0$, $w_{t}=$ $\phi w_{t-1}+z_{t}, 0<\phi<1$, and $z_{t} \sim i i d\left(0, t^{2}\right)$. The last equation can also be written in aggregate-supply form as $y_{t}=\beta\left(\pi_{t}-E_{t} \pi_{t+1}\right)+u_{t}$, with $\beta=1 / \lambda$ and $u_{t}=-w_{t} / \lambda$. Then, $\beta=\beta($ open $)$, with $\beta^{\prime} \equiv \partial \beta / \partial$ open $<0($ see below), is equivalent to $\lambda=\lambda$ (open), with $\lambda^{\prime} \equiv \partial \lambda / \partial$ (open) $>0$
} 
We make the standard assumption that policymakers solve for $\varepsilon$ after they observe $u$ but before they observe $v$, whereas the public forms inflation expectations before they observe either $u$ or $v$. The first-order condition implies that the optimum depreciation rate must satisfy

$$
\varepsilon^{D}=\frac{\alpha \beta^{2} \varepsilon^{e}-\alpha \beta u+\alpha \beta \hat{y}}{\alpha \beta^{2}+1}
$$

where $\varepsilon^{e}$ is expected depreciation and a " $D$ " superscript stands for "discretion." At equilibrium, $\varepsilon^{e}=\mathrm{E}\left(e^{D}\right)$, which gives $\varepsilon^{e}=\alpha \hat{\beta}$, and therefore

$$
\varepsilon^{D}=\alpha \beta \hat{y}-\frac{\alpha \beta}{\alpha \beta^{2}+1} u
$$

as the optimal equilibrium (“discretion") depreciation rate. Substituting (5) in (4) and (2) gives

$$
\pi^{D}=\alpha \beta \hat{y}-\frac{\alpha \beta}{\alpha \beta^{2}+1} u+v
$$

and

$$
y^{D}=\frac{1}{\alpha \beta^{2}+1} u+\beta v
$$

as the equilibrium inflation and output values, respectively.

Making use of (3), the effects of various degrees of openness are now easily derived. Equation (6) implies that average inflation will be $\bar{\pi}^{D}=\alpha \beta \hat{y}$, and therefore $\frac{d \pi^{D}}{\text { dopen }}<0$. This is, of course, identical to Romer's (1993) result, predicting lower average inflation in more open economies.

An additional result can be derived here for the average depreciation rate which, according to (5), is also given by $\bar{\varepsilon}^{D}=\alpha \beta \hat{y}$, and so $\frac{d \bar{\varepsilon}}{d o p e n}<0$, as well. Not surprisingly, because of the PPP relationship, the model predicts that more open economies will have a lower average depreciation rate. The intuition behind this is the same as with Romer's result: since the benefits of monetary expansions are lower in more open economies, the incentive to exploit the Phillips curve trade-off is lessened, and thus the average inflation bias and depreciation of the currency are reduced.

Regarding the variability of output, equation (7) implies

$$
\operatorname{Var}\left(y^{D}\right)=\left(\frac{1}{\alpha \beta^{2}+1}\right)^{2} \sigma_{u}^{2}+\beta^{2} \sigma_{v}^{2}+\left(\frac{2 \beta}{\alpha \beta^{2}+1}\right) \rho_{u v} \sigma_{u} \sigma_{v}
$$


where $\rho_{l v}$ is the correlation coefficient between $u$ and $v$. This means that the sign of $\frac{d \operatorname{Var}\left(y^{D}\right)}{d \text { open }}$ is ambiguous. Note, however, that the sign will depend on the deviations dopen
from PPP. If, for example, these deviations are small, $\sigma_{v}^{2} \rightarrow 0$, and $\frac{d \operatorname{Var}\left(y^{D}\right)}{d o p e n}>0$, as the variance will effectively depend only on the first right-had side term of (8). ${ }^{4}$ The intuition in this limiting case is as follows. As noted above, an increase in openness reduces the benefits of monetary intervention, which means that the incentive to respond to the output shock is lessened, and thus we end up with higher output volatility. The overall effect however becomes ambiguous when the second and third terms of the right-hand side of (8) are also taken into account.

Finally, with respect to exchange-rate variability, note that equation (5) implies that $\operatorname{Var}\left(\varepsilon^{D}\right)=\left(\frac{\alpha \beta}{\alpha \beta^{2}+1}\right) \sigma_{u}{ }^{2}$, and therefore that the sign of $\frac{d \operatorname{Var}\left(\varepsilon^{D}\right)}{d o p e n}$ is also
ambiguous.

\section{Data Sources and Definitions}

All data are obtained from the Penn World Table (PWT, Mark 6.0), documented in Heston, Summers, and Aden (2001; see also Summers and Heston, 1991). In addition to (i) aggregate real gross domestic product, $G D P$, the study also investigates two of its components about which the theoretical literature has made predictions: (ii) real aggregate consumption, CONS, usually the largest component, and (iii) real aggregate investment, $I N V$, usually the most volatile component. $G D P$, $C O N S$, and $I N V$ are all expressed in PPP-adjusted constant 1996 prices. The construction of the cyclical components of these aggregates will be described below.

Trade openness is captured by the variable open, which measures total trade (computed as the sum of exports, $E X$, and imports, $I M$ ) as a fraction of aggregate GDP. Specifically, for country $i$ and year $t$,

$$
\operatorname{open}_{i, t}=\frac{E X_{i, t}+I M_{i, t}}{G D P_{i, t}}
$$

Economic size is measured by the ratio of an economy's GDP to U.S. GDP,

$$
\text { size }_{i, t}=\frac{G D P_{i, t}}{G D P_{U S, t}}
$$

which captures the size of country $i$ 's economic activity relative to that of the U.S.

${ }^{4}$ Rogoff (1996) argues that deviations from PPP tend to have half lives of 3-5 years. See also Murray and Papell (2002) for more recent evidence. 
Three different methods have been used to detrend the output, consumption, and investment series of each country and estimate their cyclical components. The first is simple differencing, calculating the growth rates of real GDP, consumption, and investment as $\left(G D P_{i, t}-G D P_{i, t-1}\right) / G D P_{i, t-1},\left(C O N S_{i, t}-C O N S_{i, t-1}\right) / C O N S_{i, t-1}$ and $\left(I N V_{i, t}-\right.$ $\left.I N V_{i, t-1}\right) / I N V_{i, t-1}$, respectively.

The second method is the Hodrick-Prescott (HP) filter, proposed by Hodrick and Prescott (1980) and extensively used in the business-cycle literature. Letting $y_{i, t}=\ln \left(G D P_{i, t}\right)$, the HP filter defines the trend component $\bar{y}_{i, t}$ as the one that minimizes

$$
\sum_{t=1}^{T}\left(y_{i, t}-\bar{y}_{i, t}\right)^{2}+l \sum_{t=2}^{T-1}\left[\left(\bar{y}_{i, t+1}-\bar{y}_{i, t}\right)-\left(\bar{y}_{i, t}-\bar{y}_{i, t-1}\right)\right]
$$

for $l>0$. The cyclical component is simply $y_{i, t}-\bar{y}_{i, t}$. The method is similarly applied to the CONS and INS series. We select $l=100$, the value recommended by Kydland and Prescott (1989) for annual data.

The third method makes use of the popular Band-Pass (BP) filter proposed by Baxter and King (1995) and evaluated by Stock and Watson (1998) and Christiano and Fitzgerald (1999), who also compare its properties to those of the HP filter. The low pass (LP) filter $\alpha(L)$, which forms the basis for the band pass filter, selects a finite number of moving average weights $\alpha_{h}$ to minimize $Q=\int_{-\pi}^{4}|\delta(\omega)|^{2} d \omega$, where $\alpha(L)=\sum_{h=-K}^{K} \alpha_{h} L^{h}$ and $\alpha_{K}(\omega)=\sum_{h=-K}^{K} \alpha_{h} e^{-i \omega h}$. The LP filter uses $\alpha_{K}(\omega)$ to approximate the infinite MA filter $\beta(\omega)$. Define $\delta(\omega) \equiv \beta(\omega)-\alpha(\omega)$. Minimizing $Q$ minimizes the discrepancy between the ideal LP filter $\beta(\omega)$ and its finite representation $\alpha_{K}(\omega)$ at frequency $\omega$. The main objective of the BP filter as implemented by Baxter and King (1995) is to remove both the high frequency and low frequency component of a series, leaving the business-cycle frequencies. This is achieved by subtracting the weights of two low pass filters. We set $\omega_{L}$ and $\omega_{H}$, the lower and upper frequencies of two low pass filters, at 8 and 2, respectively. We therefore remove all fluctuations shorter than two or longer than eight years. The frequency representation of the band pass weights becomes $\alpha_{K}\left(\omega_{H}\right)-\alpha_{K}\left(\omega_{L}\right)$, and forms the basis of the Baxter-King filter which provides an alternative estimate of the trend component $\bar{y}_{i, t}$, and the cyclical component $y_{i, t}-\bar{y}_{i, t}$.

Two data sets have been constructed, depending on the length of the period for which the series defined above are available in PWT 6.0 for the various economies.

Data Set I consists of the 56 economies for which data on all series exist for each year of the 1951-1998 period. Appendix 1 provides a list of these 56 economies together with country averages for open and the standard deviation of differenced 
output (see below) over 1951-1998. ${ }^{5}$ Both developed and developing economies are represented in Data Set I. Average trade openness has ranged from $13.60 \%$ in India to $173.00 \%$ in Luxembourg, while the output volatility measure has varied from $1.78 \%$ in Norway to 12.09 in Guyana.

Data Set II consists of the 105 economies for which data on the series are available for each year of the 1960-1997 period. The trade off between the two data sets is obvious: Data Set I covers a longer time period (by ten years, roughly one fourth of the shorter period) for each country, but Data Set II contains almost twice the number of economies, including a much larger number of developing countries. Appendix 2 provides a list of these 105 economies together with country averages over 1960-1997 for the growth and open series. In Data Set II, average trade openness has ranged from $13.78 \%$ in India to $319.53 \%$ in Singapore, while the standard deviation has varied from 1.70 in Norway to 14.03 in TCD.

Both data sets will be employed in each of the estimated models below, but the results will turn out to be quite robust to the choice of data set.

\section{Empirical Evidence}

\section{A. A simple bivariate model for volatility}

We start with the simplest possible specification: a bivariate relationship between trade openness and various measures of macroeconomic volatility. Using the logarithm of openness almost always improves the fit, but doesn't change the qualitative nature of the results. Table 1 reports these estimated models for both Data Set I and Data Set II.

The top panel of Table 1, Model GDP1, measures volatility using the standard deviation of detrended real GDP. For both data sets, results are reported for each of the three detrending techniques discussed in the last section: differencing, the Hodrick-Prescott filter, and the Band-Pass filter. The estimated $\beta$ s are all positive, indicating that higher openness is associated with higher output volatility. However, with one exception (the $\beta$ for the HP-filtered series in Data Set II), the $\beta$ s are all statistically insignificant, so that the relationship between openness and business-cycle variability is not statistically different than zero.

${ }^{5}$ Country selection is dictated by data availability only. Sample means for the rest of the variables (size; the HP and BP standard deviations of output; and the DIFF, HP, and BP standard deviations of consumption and investment) are not reported in the Appendices in order to preserve space, but are available on request. 
Table 1.

\begin{tabular}{|c|c|c|c|c|c|c|}
\hline & \multicolumn{6}{|c|}{ Model GDP1: $\sigma_{G D P}=\alpha+\beta \ln ($ open $)$} \\
\hline & \multicolumn{3}{|c|}{ Data Set I } & \multicolumn{3}{|c|}{ Data Set II } \\
\hline & DIFF & HP Filter & BP Filter & DIFF & HP Filter & BP Filter \\
\hline \multirow[t]{2}{*}{$\alpha$} & $0.048 * *$ & $0.043^{* *}$ & $0.028 * *$ & $0.060 * *$ & $0.053 * *$ & $0.036^{* *}$ \\
\hline & $(0.006)$ & $(0.005)$ & $(0.004)$ & $(0.004)$ & $(0.007)$ & $(0.002)$ \\
\hline \multirow[t]{2}{*}{$\beta$} & 0.004 & 0.004 & 0.002 & 0.007 & $0.007 *$ & 0.003 \\
\hline & $(0.006)$ & $(0.004)$ & $(0.004)$ & $(0.004)$ & $(0.003)$ & $(0.003)$ \\
\hline$R^{2}$ & 0.014 & 0.011 & 0.010 & 0.020 & 0.027 & 0.013 \\
\hline \multirow[t]{4}{*}{$N$} & 56 & 56 & 56 & 105 & 105 & 105 \\
\hline & \multicolumn{6}{|c|}{ Model INV1: $\sigma_{I N V}=\kappa+\lambda \ln ($ open $)$} \\
\hline & \multicolumn{3}{|c|}{ Data Set I } & \multicolumn{3}{|c|}{ Data Set II } \\
\hline & DIFF & HP Filter & BP Filter & DIFF & HP Filter & BP Filter \\
\hline \multirow[t]{2}{*}{$\kappa$} & $0.191 * *$ & $0.151 * *$ & $0.109 * *$ & $0.232 * *$ & $0.181 * *$ & $0.127 * *$ \\
\hline & $(0.020)$ & $(0.013)$ & $(0.010)$ & $(0.019)$ & $(0.012)$ & $(0.009)$ \\
\hline \multirow[t]{2}{*}{$\lambda$} & 0.030 & 0.020 & 0.013 & 0.033 & 0.023 & 0.010 \\
\hline & $(0.018)$ & $(0.012)$ & $(0.009)$ & $(0.020)$ & $(0.013)$ & $(0.010)$ \\
\hline$R^{2}$ & 0.049 & 0.047 & 0.033 & 0.023 & 0.030 & 0.010 \\
\hline \multirow[t]{4}{*}{$\mathrm{N}$} & 56 & 56 & 56 & 105 & 105 & 105 \\
\hline & \multicolumn{6}{|c|}{ Model CONS1: $\sigma_{C O N S}=\vartheta+\zeta \ln ($ open $)$} \\
\hline & \multicolumn{3}{|c|}{ Data Set I } & \multicolumn{3}{|c|}{ Data Set II } \\
\hline & DIFF & HP Filter & BP Filter & DIFF & HP Filter & BP Filter \\
\hline \multirow[t]{2}{*}{$\vartheta$} & $0.065 * *$ & $0.054 * *$ & $0.038^{* *}$ & $0.094 * *$ & $0.077 * *$ & $0.055^{* *}$ \\
\hline & $(0.011)$ & $(0.007)$ & $(0.006)$ & $(0.010)$ & $(0.007)$ & $(0.005)$ \\
\hline \multirow[t]{2}{*}{$\zeta$} & 0.012 & 0.010 & 0.007 & $0.026 * *$ & $0.022 * *$ & $0.015 * *$ \\
\hline & $(0.010)$ & $(0.007)$ & $(0.006)$ & $(0.009)$ & $(0.006)$ & $(0.005)$ \\
\hline $\mathrm{R}^{2}$ & 0.037 & 0.041 & 0.036 & 0.073 & 0.095 & 0.086 \\
\hline $\mathrm{N}$ & 56 & 56 & 56 & 105 & 105 & 105 \\
\hline
\end{tabular}

Notes: $\sigma_{G D B}, \sigma_{I N}$ and $\sigma_{C O N S}$ are the standard deviations of the cyclical components of GDP, investment, and consumption, respectively. DIFF refers to differencing; $H P$ to the Hodrick-Prescott filter, using $l=$ $100 ; B P$ to the Band-Pass filter, implemented as in Baxter and King (1995) using $K=2$ lags. See the text for details. Estimated heteroskedasticity-consistent (White, 1980) standard errors in parentheses. $N$ is the number of observations. $* *$ and $*$ denote statistical significance at the $1 \%$ and $5 \%$ significance levels.

Similar results are obtained for investment and consumption in the middle and bottom panels of Table 1 . The volatility of investment is the dependent variable in the middle panel's Model INVI. The estimated $\lambda$, representing the effects of openness on the standard deviation of investment, are all positive, but not statistically significant. It appears then that openness is not statistically significantly related to investment variability. The same result holds in Data Set I for consumption variability at the bottom panel of Table1, where $\zeta$ captures the effects of openness in Model CONS1. For Data Set II, however, the estimated $\zeta$ s are both 
positive and statistically significant, for all three detrending methods.

Summing up the evidence from the bivariate models of Table 1, trade openness is shown to be positively related to various measures of macroeconomic volatility. This is consistent with the theoretical predictions of Razin, Sadka, and Coury (2002, 2003) and Gali and Monacelli (1999). This positive relationship, however, is only statistically significant for consumption variability and only in Data Set II; the relationship is insignificant for the variability of GDP and investment in both data sets, and of consumption in Data Set I. Overall, these results confirm the consensus empirical view that trade openness doesn't have much to do with macroeconomic volatility.

\section{B. Including economic size in the volatility models}

This section asks whether the results obtained so far may be sensitive to the inclusion of a measure of economic size in the volatility regressions. There are good reasons to think that economic size and openness are related. Clearly, the larger the economy, the greater the degree to which it will be self-sufficient, reducing trade openness; whereas, a smaller economy will normally be more dependent on foreign trade, resulting in greater trade openness. For a theoretical derivation of such an inverse relationship between steady-state trade openness and economic size in the context of an optimizing growth model, see Spolaore and Wacziarg (2002).

Empirically, the inverse relationship between size and openness is decisively present in both of our data sets. In particular, the correlation coefficient between (the logarithms of) the two variables is -0.618 in Data Set I and -0.477 in Data Set II, establishing strong negative correlations in both cases. Econometrically, of course, these correlations mean that if economic size is a relevant explanatory variable in the volatility regressions, omitting it (as the regressions of Table 1 have done) will bias the results.

Table 2 reports the estimated regressions that include economic size. The top panel of Table 2, Model GDP2, uses the standard deviation of detrended real GDP as the dependent variable. The results are again reported for both data sets and for each of the three detrending methods. The $\beta$ s continue to represent the volatility effects of openness, and the $\gamma$ s capture those of economic size. Note that now the estimated $\beta$ s are all negative, indicating that higher openness is associated with lower output volatility, and this relationship is strongly statistically significant in Data Set $I$. In addition, the estimated $\gamma$ s are also all negative, and statistically 
Table 2.

\begin{tabular}{|c|c|c|c|c|c|c|}
\hline & \multicolumn{6}{|c|}{ Model GDP2: $\sigma_{G D P}=\alpha+\beta \ln ($ open $)+\gamma \ln ($ size $)$} \\
\hline & \multicolumn{3}{|c|}{ Data Set I } & \multicolumn{3}{|c|}{ Data Set II } \\
\hline & DIFF & HP Filter & BP Filter & DIFF & HP Filter & BP Filter \\
\hline \multirow[t]{2}{*}{$\alpha$} & -0.001 & -0.005 & -0.004 & 0.007 & 0.007 & 0.001 \\
\hline & $(0.007)$ & $(0.006)$ & $(0.005)$ & $(0.008)$ & $(0.007)$ & $(0.005)$ \\
\hline \multirow[t]{2}{*}{$\beta$} & $-0.012 * *$ & $-0.012 * *$ & $-0.008 * *$ & -0.007 & -0.005 & -0.006 \\
\hline & $(0.004)$ & $(0.003)$ & $(0.003)$ & $(0.005)$ & $(0.004)$ & $(0.003)$ \\
\hline$\gamma$ & $-0.009 * *$ & $-0.008 * *$ & $-0.006 * *$ & $-0.009 * *$ & $-0.008 * *$ & $-0.006^{* *}$ \\
\hline \multirow{2}{*}{$\mathrm{R}^{2}$} & $(0.002)$ & $(0.001)$ & $(0.001)$ & $(0.001)$ & $(0.001)$ & $(0.001)$ \\
\hline & 0.330 & 0.389 & 0.324 & 0.322 & 0.346 & 0.332 \\
\hline \multirow[t]{4}{*}{$\mathrm{N}$} & 56 & 56 & 56 & 105 & 105 & 105 \\
\hline & \multicolumn{6}{|c|}{ Model INV2: $\sigma_{I N V}=\kappa+\lambda \ln ($ open $)+\mu \ln ($ size $)$} \\
\hline & \multicolumn{3}{|c|}{ Data Set I } & \multicolumn{3}{|c|}{ Data Set II } \\
\hline & DIFF & HP Filter & BP Filter & DIFF & HP Filter & BP Filter \\
\hline \multirow[t]{2}{*}{$\kappa$} & -0.033 & -0.007 & -0.012 & -0.021 & 0.006 & -0.007 \\
\hline & $(0.022)$ & $(0.015)$ & $(0.012)$ & $(0.033)$ & $(0.018)$ & $(0.015)$ \\
\hline \multirow[t]{2}{*}{$\lambda$} & $-0.043 * *$ & $-0.032 * *$ & $-0.026 * *$ & $-0.034 *$ & $-0.023 *$ & $-0.025 * *$ \\
\hline & $(0.011)$ & $(0.008)$ & $(0.006)$ & $(0.016)$ & $(0.009)$ & $(0.007)$ \\
\hline \multirow[t]{2}{*}{$\mu$} & $-0.040 * *$ & $-0.028 * *$ & $-0.021 * *$ & $-0.041 * *$ & $-0.029 * *$ & $-0.022 * *$ \\
\hline & $(0.005)$ & $(0.003)$ & $(0.002)$ & $(0.006)$ & $(0.003)$ & $(0.003)$ \\
\hline$R^{2}$ & 0.517 & 0.540 & 0.507 & 0.338 & 0.446 & 0.400 \\
\hline \multirow[t]{4}{*}{$N$} & 56 & 56 & 56 & 105 & 105 & 105 \\
\hline & \multicolumn{6}{|c|}{ Model INV2: $\sigma_{C O N S}=\vartheta+\zeta \ln ($ open $)+\xi \ln ($ size $)$} \\
\hline & \multicolumn{3}{|c|}{ Data Set I } & \multicolumn{3}{|c|}{ Data Set II } \\
\hline & DIFF & HP Filter & BP Filter & DIFF & HP Filter & BP Filter \\
\hline \multirow[t]{2}{*}{$\vartheta$} & -0.020 & -0.012 & $-0.015^{*}$ & -0.011 & -0.003 & -0.007 \\
\hline & $(0.011)$ & $(0.009)$ & $(0.007)$ & $(0.013)$ & $(0.009)$ & $(0.007)$ \\
\hline \multirow[t]{2}{*}{$\zeta$} & $-0.016^{*}$ & $-0.012 *$ & $-0.010^{*}$ & -0.002 & 0.001 & -0.001 \\
\hline & $(0.007)$ & $(0.005)$ & $(0.004)$ & $(0.007)$ & $(0.006)$ & $(0.005)$ \\
\hline \multirow[t]{2}{*}{$\xi$} & $-0.015 * *$ & $-0.012 * *$ & $-0.009 * *$ & $-0.017 * *$ & $-0.013 * *$ & $-0.010 * *$ \\
\hline & $(0.003)$ & $(0.002)$ & $(0.001)$ & $(0.002)$ & $(0.002)$ & $(0.001)$ \\
\hline$R^{2}$ & 0.366 & 0.379 & 0.383 & 0.354 & 0.406 & 0.425 \\
\hline$N$ & 56 & 56 & 56 & 105 & 105 & 105 \\
\hline
\end{tabular}

Notes: See Table 1.

significant in every specification. The negative $\gamma$ s imply that business-cycle variability decreases with economic size, an interesting finding in its own right. But it also explains why openness may misleadingly appear to be positively correlated, or uncorrelated, with economic variability when economic size is omitted as an explanatory variable: recall that openness and size are themselves negatively correlated.

The results for investment and consumption when economic size is included are 
reported in the middle and bottom panels of Table 2 . The volatility of investment is the dependent variable in the middle panel's Model INV2. The estimated $\lambda \mathrm{s}$, representing again the effects of openness on the standard deviation of investment, are now all negative, and all statistically significant. Contrary to the evidence of Table 1 and the theoretical predictions of Razin, Sadka, and Coury (2002, 2003), it is clear that investment variability is decreasing with openness, once economic size has been controlled for. As for the effects of economic size, the estimated $\mu$ s are all negative and also strongly statistically significant, implying that the volatility of investment is lower for larger economies.

Similar results are obtained for consumption variability at the bottom panel of Table 2. Note first that economic size is again strongly and significantly negatively correlated with the volatility of consumption. In addition, with size included in the models, the estimated $\xi$ s, capturing the effects of openness as before, are negative (with the single exception of the HP-filtered series for Data Set II) and statistically significant for Data Set I. Once again, the sign of the openness coefficient changes from positive to negative when economic size is included in the regressions. As for the estimated effects of economic size, the estimated $\xi \mathrm{s}$ are all statistically significantly negative, implying that consumption volatility also decreases with size.

Reviewing the evidence of Table 2, the critical finding is that economic size matters and that it is statistically significantly negatively correlated with the variability of output, investment, and consumption: larger economies exhibit less macroeconomic volatility. An additional implication of this finding, since economic size turns out to be also strongly negatively correlated with openness, is that the regressions of Table 1 (and many volatility regressions in the literature which have not included size as an explanatory variable) suffer from omitted variable bias. When size is controlled for, as in Table 2, trade openness is found to be negatively and, generally, statistically significantly related to various measures of macroeconomic volatility. This is inconsistent with the theoretical predictions of Razin, Sadka, and Coury $(2002,2003)$ and Gali and Monacelli (1999), but consistent with a simple Romer-type model, such as the one outlined in section $2{ }^{6}$

\section{Exchange Rate models}

Finally, Tables 3 and 4 examine the effects of openness on the average rate of

\footnotetext{
${ }^{6}$ It is perhaps worth noting that the $R^{2} \mathrm{~s}$ of the regressions of Table 2 range from 0.322 to 0.540 , suggesting that a remarkably high portion (one-third to one-half) of macroeconomic volatility is "explained" by just these two variables: economic size and trade openness.
} 
Table 3

\begin{tabular}{|c|c|c|c|c|c|c|}
\hline & \multicolumn{6}{|c|}{ Model E1: $\sigma_{E}=\chi+\phi \ln ($ open $)$} \\
\hline & \multicolumn{3}{|c|}{ Data Set I } & \multicolumn{3}{|c|}{ Data Set II } \\
\hline & DIFF & HP Filter & BP Filter & DIFF & HP Filter & BP Filter \\
\hline \multirow[t]{2}{*}{$\chi$} & 1237.2 & $0.156^{*}$ & $0.084 * *$ & 639.45 & $0.148 * *$ & $0.084 * *$ \\
\hline & $(1205)$ & $(0.064)$ & $(0.029)$ & $(586.9)$ & $(0.032)$ & $(0.015)$ \\
\hline \multirow[t]{2}{*}{$\phi$} & 602.5 & -0.082 & -0.042 & 127.71 & $-0.089 *$ & $-0.049 *$ \\
\hline & (710.9) & $(0.069)$ & $(0.034)$ & $(294.9)$ & $(0.043)$ & $(0.022)$ \\
\hline$R^{2}$ & 0.004 & 0.022 & 0.010 & 0.001 & 0.033 & 0.044 \\
\hline \multirow[t]{3}{*}{$N$} & 56 & 56 & 56 & 105 & 105 & 105 \\
\hline & \multicolumn{6}{|c|}{ Model $\Delta \mathrm{E} 1: \ln (\overline{\Delta E})=\pi+\rho \ln ($ open$)$} \\
\hline & & Data Set I & & & Data Set II & \\
\hline \multirow[t]{2}{*}{$\pi$} & & $1.361 * *$ & & & $1.414 * *$ & \\
\hline & & $(0.519)$ & & & $(0.263)$ & \\
\hline \multirow[t]{2}{*}{$\rho$} & & -0.988 & & & -0.996 & \\
\hline & & $(0.522)$ & & & $(0.322)$ & \\
\hline$R^{2}$ & & 0.065 & & & 0.087 & \\
\hline$N$ & & 56 & & & 105 & \\
\hline
\end{tabular}

Notes: $\sigma_{E}$ is the standard deviation of the cyclical component of the exchange rate, E; and $\overline{\Delta E}$ is the average depreciation rate with respect to the U.S. dollar. DIFF refers to differencing; $H P$ to the HodrickPrescott filter, using $l=100 ; B P$ to the Band-Pass filter, implemented as in Baxter and King (1995) using $K=2$ lags. See the text for details. Estimated heteroskedasticity-consistent (White, 1980) standard errors in parentheses. $N$ is the number of observations. $* *$ and $*$ denote statistical significance at the $1 \%$ and $5 \%$ significance levels.

depreciation and the volatility of the exchange rate. Following the pattern of Tables 1 and 2, Table 3 estimates simple bivariate models, while Table 4 adds economic size.

The top panel of Table 3, Model E1, has the standard deviation of the exchange rate as the dependent variable. For both data sets, the parameter $\phi$, which measures the effect of openness, is positive but statistically insignificant for the differenced series, and negative for the HP- and BP-filtered ones (but significant only in Data Set $I I)$. Model $\triangle E 1$, at the bottom panel of Table 3, looks at the average depreciation rate, with $\rho$ representing the effects of openness. Consistent with the predictions of the theoretical model of section 2, the estimated $\rho$ s are negative for both data sets, but they are not statistically significantly different from zero.

Table 4 includes economic size in the estimated models. Once again, this makes a difference for the results, though it is somewhat less pronounced than the difference between the results of Tables 1 and 2. Focusing on Model E2 at the top panel of Table 4, we see that exchange-rate variability is inversely related to both trade openness and economic size: the estimated $\phi$ s and $\psi$ s re negative for both data sets and all three detrending methods (though not significant for the differenced series). 
Table 4

\begin{tabular}{|c|c|c|c|c|c|c|}
\hline & \multicolumn{6}{|c|}{ Model E2: $\sigma_{E}=\chi+\phi \ln ($ open $)+\psi \ln ($ size $)$} \\
\hline & \multicolumn{3}{|c|}{ Data Set I } & \multicolumn{3}{|c|}{ Data Set II } \\
\hline & DIFF & HP Filter & BP Filter & DIFF & HP Filter & BP Filter \\
\hline \multirow{7}{*}{$R^{2}$} & -2119.7 & $-0.230 *$ & -0.105 & -184.13 & 0.068 & 0.037 \\
\hline & $(1927.6)$ & $(0.124)$ & $(0.060)$ & $(253.8)$ & $(0.046)$ & $(0.024)$ \\
\hline & -504.04 & $-0.209 * *$ & $-0.105 * *$ & -92.65 & $-0.111 * *$ & $-0.061 * *$ \\
\hline & $(457.5)$ & $(0.074)$ & $(0.038)$ & $(173.6)$ & $(0.040)$ & $(0.021)$ \\
\hline & -592.08 & $-0.068 *$ & $-0.033 * *$ & -134.8 & -0.013 & -0.008 \\
\hline & $(539.7)$ & $(0.028)$ & $(0.013)$ & $(117.9)$ & $(0.009)$ & $(0.005)$ \\
\hline & 0.027 & 0.106 & 0.122 & 0.003 & 0.040 & 0.053 \\
\hline \multirow[t]{3}{*}{$\mathrm{N}$} & 56 & 56 & 56 & 105 & 105 & 105 \\
\hline & \multicolumn{6}{|c|}{ Model $\Delta \mathrm{E} 2: \ln (\overline{\Delta E})=\pi+\rho \ln ($ open $)+\tau \ln ($ size $)$} \\
\hline & \multicolumn{3}{|c|}{ Data Set I } & \multicolumn{3}{|c|}{ Data Set II } \\
\hline \multirow[t]{2}{*}{$\pi$} & \multirow{2}{*}{\multicolumn{3}{|c|}{$\begin{array}{c}-3.005 * * \\
(1.086)\end{array}$}} & \multicolumn{3}{|c|}{0.498} \\
\hline & & & & \multicolumn{3}{|c|}{$(0.629)$} \\
\hline \multirow[t]{2}{*}{$\rho$} & \multicolumn{3}{|c|}{$-2.415 * *$} & \multicolumn{3}{|c|}{$-1.270 * *$} \\
\hline & \multicolumn{3}{|c|}{$(0.626)$} & \multicolumn{3}{|c|}{$(0.346)$} \\
\hline \multirow[t]{2}{*}{$\tau$} & \multicolumn{3}{|c|}{$-0.736 * *$} & & -0.139 & \\
\hline & \multicolumn{3}{|c|}{$(0.182)$} & \multicolumn{3}{|c|}{$(0.092)$} \\
\hline$R^{2}$ & \multicolumn{3}{|c|}{0.290} & \multicolumn{3}{|c|}{0.103} \\
\hline$N$ & \multicolumn{3}{|c|}{56} & \multicolumn{3}{|c|}{105} \\
\hline
\end{tabular}

Notes: See Table 3.

At the bottom of Table 4, the average depreciation rate is the dependent variable in Model $\triangle E 2$. Just as in Model $\triangle E 1$ of Table 3, the effects of openness are negative, but the estimated $\rho$ s are now larger (in absolute value) and statistically significant. Note again that this is consistent with the predictions of the Romer-type model of section 2. With respect to economic size, the estimated $\tau$ is also negative (though insignificantly so for Data Set II), indicating that depreciation rates are lower for larger economies.

Summarizing the evidence of Tables 3 and 4, it is apparent once again that the inclusion of economic size in the models clarifies and sharpens the role of openness. Specifically, when both variables are included, they are both found to have negative effects on the average depreciation rate and the volatility of the exchange rate.

\section{Discussion and Conclusions}

This paper investigated the effects of trade openness on macroeconomic volatility. While the number of theoretical studies that have dealt with the issue is small, it is clear that the relationship is ambiguous. At the most basic level, the ambiguity 
stems from the fact that increased openness may better insulate an economy from the effects of domestic shocks (by allowing more of their effects to be "exported" to the country's trading partners), but it will also raise the economy's vulnerability to foreign shocks, so that the overall outcome is unclear. More sophisticated models that take into account the optimal responses of monetary policy and the effects of openness on the potency of monetary policy have also mixed and ambiguous results. This has been demonstrated in this paper in the context of a very simple model that combines the central elements of Romer (1993) and Obstfeld and Rogoff (1996).

The question, therefore, has to be resolved empirically, and this has been the main focus of the paper. Specifically, the relationship between trade openness and macroeconomic volatility has been examined here using annual data from (i) the 1951-1998 period for a sample of 56 economies, and (ii) the 1960-1997 period for a sample of 105 economies. Both data sets include countries at various stages of development. Macroeconomic volatility is measured here by the variances of cyclical (detrended) output, consumption, investment, and the exchange rate.

The results show that the bivariate openness-volatility relationship is weak, fragile, and generally statistically insignificant, regardless of the data set, detrending method, or volatility measure used. This confirms the empirical literature's difficulty to find conclusive evidence of a strong relationship.

However, when economic size is included in the estimated models, the effects of both openness and economic size on macroeconomic volatility are found to be negative, sizable, and statistically significant. The reason for the resolution of the (empirical) ambiguity is that economic size is negatively correlated with openness, and so failure to include it in the regression biases the results. In addition, the average depreciation rate is shown to be inversely related to both economic size and trade openness.

The policy implications of the paper's results are straightforward. While there is not much economic policy can do to change an economy's relative size (at least in the short run), for most countries no such limitations exist regarding openness. Policies, national or global, which facilitate trade among countries, should also promote macroeconomic stability. ${ }^{7}$ From successful trade rounds that reduce various forms of protection, to bilateral or multilateral agreements (such as NAFTA) that dismantle trade barriers, to the trade liberalization that is one of the characteristics

${ }^{7}$ In addition to enhancing growth rates, if the empirical literature on openness and growth (see footnote $1)$ is correct. 
of globalization, the effects on macroeconomic stability (as well as on growth) are positive and sizable.

In terms of the theoretical importance of the results, the main implications are two. First, knowing that trade openness is in fact inversely related to macroeconomic volatility can help narrow down the set of useful theoretical models simply by ruling out the mechanisms that are inconsistent with these negative correlations. Second, the fact that economic size and trade openness have empirical effects on volatility that are identifiably distinct means that we need theoretical approaches that distinguish between the two concepts and their economic effects, which has not been usually the case in most of the theoretical literature.

\section{Acknowledgments}

I would like to thank Alfred Guender, David Van Hoose, and participants of the 2004 ASSA-IAES conference in San Diego for helpful comments and suggestions. Errors and omissions are of course mine.

Received 19 July 2005, Accepted 12 December 2005

\section{References}

Barro, Robert J. and Xavier Sala-i-Martin. (1995), Economic Growth. McGraw-Hill, New York. Baxter, Marianne and Robert G. King. (1995), "Measuring Business Cycles: Approximate Band-Pass Filters for Economic Time Series", NBER Working Paper No.5022, February. Buch, Claudia M., Jörg Döpke, and Christian Peidrzioch (2002), "Financial Openness and Business Cycle Volatility", Kiel working paper No. 1121, Kiel Institute for World Economics, July.

Christiano, Lawrence J. and Terry J. Fitzgerald. (1999), “The Band Pass Filter”, NBER Working Paper, No. 7257, July.

Dollar, David. (1992), “Outward-Oriented Developing Economies Really Do Grow More Rapidly: Evidence from 95 LDCs, 1976-85”, Economic Development and Cultural Change, 40, 523-544.

Edwards, Sebastian. (1998), "Openness, Productivity and Growth: What Do We Really Know?", Economic Journal, 108, 383-398.

Frankel, J. and D. Romer. (1999), "Does Trade Cause Growth?", American Economic Review, 89, 379-399.

Gali, Jordi and Tommaso Monacelli. (1999), "Optimal Monetary Policy and ExchangeRate Volatility in a Small Open Economy”, working paper, November. 
Grossman, Gene and Elhanan Helpman. (1991), Innovation and Growth in the World Economy. MIT Press.

Guender, Alfred V. (2003), "Stabilizing Properties of Discretionary Monetary Policies in a Small Open Economy: Domestic vs CPI Inflation Targets", University of Canterbury, working paper.

Hau, Harald. (2002), "Real Exchange Rate Volatility and Economic Openness: Theory and Evidence", Journal of Money, Credit, and Banking, 34, 611-630.

Heston, Alan, Robert Summers and Bettina Aden. (2001), "Penn World Table, Version 6.0.", Center for International Comprisons at the University of Pennsylvania (CICUP), December.

Hodrick, Robert J. and Edward C. Prescott. (1980), "Postwar U.S. Business Cycles: An Empirical Investigation", Discussion Paper 451, Carnegie Mellon University.

IMF. (2002), "Trade and Financial Integration", In World Economic Outlook: Trade and Finance, September.

Irwin, Douglas A. and Marko Terviö. (2002), "Does Trade Raise Income? Evidence from the Twentieth Century", Journal of International Economics, 58, 1-18.

Karras, Georgios and Frank Song. (1996), "Sources of Business-Cycle Volatility: An Exploratory Study on A Sample of OECD Countries", Journal of Macroeconomics, 18, 621-637.

Kose, M. Ayhan, Eswar S. Prasad, and Marco E. Terrones. (2003), "Financial Integration and Macroeconomic Volatility", IMF Staff Papers, 50, 119-142.

Kydland, Finn E. and Edward C. Prescott. (1989), "A Fortran Subroutine for Efficiently Computing HP-Filtered Time Series", Research Memorandum, Federal Reserve Bank of Minneapolis, April.

Murray, Christian J. and David H. Papell. (2002), "The Purchasing Power Parity Persistence Paradigm", Journal of International Economics, 56, 1-19.

Obstfeld, Maurice and Kenneth Rogoff. (1996), Foundations of International Macroeconomics. MIT Press.

Razin, Assaf and Andrew K. Rose. (1994), "Business-Cycle Volatility and Openness: An Exploratory Cross-Sectional Analysis", in Capital Mobility: The Impact on Consumption, Investment, and Growth, L.Leiderman and A.Razin (eds.), Cambridge University Press.

Razin, Assaf, Efraim Sadka, and Tarek Coury. (2002), "Trade Openness and Investment Instability", NBER working paper, No.8827, March.

Razin, Assaf, Efraim Sadka, and Tarek Coury. (2003), "Trade Openness, Investment Instability and Terms-of-Trade Volatility", Journal of International Economics, 61, 285-306.

Rogoff, Kenneth. "The Purchasing Power Parity Puzzle", Journal of Economic Literature, 34, 1996, 647-668.

Romer, David. "Openness and Inflation: Theory and Evidence", Quarterly Journal of Economics, 108, 1993, 869-903.

Spolaore, Enrico and Romain Wacziarg. "Borders and Growth", NBER working paper No. 9223, September 2002.

Stock, James H. and Mark W. Watson. "Business Cycle Fluctuations in U.S. Macroeconomic 
Time Series", NBER Working Paper No. 6528, April 1998.

Summers, Robert and Alan Heston. "The Penn World Table (Mark 5): An Expanded Set of International Comparisons, 1950-1988”, Quarterly Journal of Economics, 106, 1991, 327-368.

White, Halbert. "A Heteroskedasticity-Consistent Covariance Matrix Estimator and Direct Test for Heteroskedasticity", Econometrica, 48, 1980, 817-838.

Appendix 1: Data Set I

\begin{tabular}{lccccc}
\hline \multicolumn{5}{c}{ Averages over 1951 -1998 } & \\
\hline Country & $\sigma_{G D P}$ & open & Country & $\sigma_{G D P}$ & open \\
\hline 1 ARG & $6.36 \%$ & $14.34 \%$ & 29 ITA & $2.66 \%$ & $36.14 \%$ \\
2 AUS & 3.30 & 34.04 & 30 JPN & 3.98 & 21.33 \\
3 AUT & 2.78 & 61.87 & 31 KEN & 6.60 & 62.72 \\
4 BEL & 2.32 & 107.08 & 32 LKA & 3.48 & 74.72 \\
5 BOL & 4.27 & 52.62 & 33 LUX & 3.66 & 173.00 \\
6 BRA & 4.26 & 16.05 & 34 MAR & 6.06 & 45.06 \\
7 CAN & 2.93 & 48.33 & 35 MEX & 4.34 & 26.22 \\
8 CHE & 4.19 & 62.77 & 36 MUS & 6.80 & 98.13 \\
9 CHL & 6.37 & 40.48 & 37 NGA & 9.26 & 41.00 \\
10 COL & 2.46 & 29.56 & 38 NIC & 8.68 & 63.11 \\
11 CRI & 4.91 & 66.44 & 39 NLD & 2.93 & 95.40 \\
12 DNK & 2.83 & 65.04 & 40 NOR & 1.80 & 73.96 \\
13 DOM & 6.75 & 52.79 & 41 PAK & 4.09 & 31.45 \\
14 ECU & 4.39 & 45.32 & 42 PAN & 4.92 & 81.49 \\
15 EGY & 3.92 & 48.03 & 43 PER & 6.40 & 34.70 \\
16 ESP & 3.83 & 29.47 & 44 PHL & 3.74 & 46.47 \\
17 ETH & 4.84 & 22.58 & 45 PRY & 5.03 & 45.52 \\
18 FIN & 3.73 & 51.43 & 46 SLV & 4.63 & 53.71 \\
19 FRA & 2.16 & 35.98 & 47 SWE & 2.28 & 55.04 \\
20 GBR & 2.06 & 48.79 & 48 THA & 5.94 & 50.19 \\
21 GRC & 3.62 & 31.93 & 49 TTO & 6.73 & 95.40 \\
22 GTM & 2.36 & 36.45 & 50 TUR & 5.33 & 20.31 \\
23 GUY & 12.09 & 135.17 & 51 TWN & 2.83 & 69.44 \\
24 HND & 3.10 & 62.88 & 52 UGA & 7.95 & 34.23 \\
25 IND & 3.27 & 13.59 & 53 URY & 5.43 & 34.35 \\
26 IRL & 3.38 & 94.33 & 54 USA & 2.40 & 14.80 \\
27 ISL & 4.35 & 68.87 & 55 VEN & 5.78 & 46.60 \\
28 ISR & 5.16 & 69.48 & 56 ZAF & 3.15 & 51.71 \\
\hline
\end{tabular}

Note: $\sigma_{G D P}$ is the standard deviation of the GDP growth rate, and open is the average openness (exports plus imports) as a fraction of GDP. Both statistics are computed over 1951-1998. 


\section{Appendix 2: Data Set II}

\begin{tabular}{|c|c|c|c|c|c|c|c|c|}
\hline \multicolumn{9}{|c|}{ Averages over 1960-1997 } \\
\hline Country & $\sigma_{G D P}$ & open & Country & $\sigma_{G D P}$ & open & Country & $\sigma_{G D P}$ & open \\
\hline $1 \mathrm{ARG}$ & \multicolumn{2}{|c|}{$6.56 \% 14.68 \%$} & $36 \mathrm{GIN}$ & $3.95 \%$ & $47.51 \%$ & $71 \mathrm{NIC}$ & $9.02 \%$ & 64.22 \\
\hline 2 AUS & 2.51 & 34.19 & 37 GMB & 6.40 & 101.57 & 72 NLD & 2.21 & 96.42 \\
\hline 3 AUT & 2.07 & 65.94 & 38 GNB & 8.80 & 44.22 & 73 NOR & 1.78 & 74.07 \\
\hline 4 BDI & 8.77 & 30.22 & 39 GRC & 3.65 & 34.89 & 74 NPL & 3.42 & 28.45 \\
\hline $5 \mathrm{BEL}$ & 2.39 & 114.43 & 40 GTM & 2.43 & 38.56 & $75 \mathrm{NZL}$ & 3.75 & 53.89 \\
\hline $6 \mathrm{BEN}$ & 3.91 & 52.77 & $41 \mathrm{GUY}$ & 12.85 & 143.99 & 76 PAK & 3.87 & 32.82 \\
\hline $7 \mathrm{BFA}$ & 4.67 & 33.83 & $42 \mathrm{HKG}$ & 4.90 & 203.49 & 77 PAN & 5.40 & 82.71 \\
\hline 8 BGD & 5.06 & 19.90 & 43 HND & 3.09 & 65.22 & 78 PER & 6.66 & 33.40 \\
\hline $9 \mathrm{BOL}$ & 3.96 & 56.05 & $44 \mathrm{IDN}$ & 4.29 & 40.85 & 79 PHL & 3.74 & 50.25 \\
\hline $10 \mathrm{BRA}$ & 4.47 & 16.25 & $45 \mathrm{IND}$ & 3.48 & 13.78 & 80 PNG & 4.33 & 82.26 \\
\hline $11 \mathrm{BWA}$ & 7.21 & 87.30 & 46 IRL & 3.03 & 99.37 & 81 PRT & 3.43 & 58.85 \\
\hline $12 \mathrm{CAF}$ & 6.75 & 56.53 & 47 IRN & 6.67 & 38.07 & 82 PRY & 4.99 & 47.78 \\
\hline $13 \mathrm{CAN}$ & 2.77 & 50.04 & 48 ISL & 3.94 & 71.59 & 83 ROM & 6.54 & 41.46 \\
\hline $14 \mathrm{CHE}$ & 3.79 & 64.77 & 49 ISR & 4.83 & 80.85 & 84 RWA & 10.12 & 29.81 \\
\hline $15 \mathrm{CHL}$ & 6.72 & 43.96 & 50 ITA & 2.61 & 39.13 & $85 \mathrm{SEN}$ & 3.70 & 62.73 \\
\hline $16 \mathrm{CHN}$ & 5.03 & 16.01 & $51 \mathrm{JAM}$ & 5.41 & 92.25 & 86 SGP & 9.16 & 319.52 \\
\hline 17 CIV & 6.81 & 69.10 & 52 JOR & 8.2398 .83 & 87 SLV & 5.08 & 55.52 & \\
\hline $18 \mathrm{CMR}$ & 7.75 & 47.80 & $53 \mathrm{JPN}$ & 3.91 & 21.29 & $88 \mathrm{SWE}$ & 2.43 & 56.75 \\
\hline $19 \mathrm{COG}$ & 6.45 & 102.30 & $54 \mathrm{KEN}$ & 6.62 & 60.78 & $89 \mathrm{SYC}$ & 7.10 & 107.58 \\
\hline $20 \mathrm{COL}$ & 2.24 & 29.69 & $55 \mathrm{KOR}$ & 3.83 & 53.65 & $90 \mathrm{SYR}$ & 12.64 & 48.58 \\
\hline $21 \mathrm{COM}$ & 8.08 & 58.42 & 56 LKA & 3.41 & 69.26 & $91 \mathrm{TCD}$ & 14.03 & 40.10 \\
\hline $22 \mathrm{CPV}$ & 8.85 & 59.23 & 57 LSO & 5.68 & 117.66 & $92 \mathrm{TGO}$ & 9.19 & 84.59 \\
\hline 23 CRI & 4.42 & 69.23 & 58 LUX & 3.93 & 177.16 & 93 ТНА & 4.31 & 52.36 \\
\hline $24 \mathrm{DNK}$ & 2.38 & 64.60 & $59 \mathrm{MAR}$ & 6.24 & 44.84 & 94 TTO & 7.04 & 87.99 \\
\hline $25 \mathrm{DOM}$ & 7.43 & 53.29 & $60 \mathrm{MDG}$ & 3.42 & 38.22 & 95 TUR & 4.26 & 22.59 \\
\hline $26 \mathrm{DZA}$ & 10.53 & 54.13 & $61 \mathrm{MEX}$ & 4.49 & 27.07 & 96 TWN & 2.90 & 79.50 \\
\hline $27 \mathrm{ECU}$ & 4.71 & 47.26 & $62 \mathrm{MLI}$ & 5.70 & 42.81 & 97 TZA & 9.06 & 35.72 \\
\hline $28 \mathrm{EGY}$ & 3.58 & 49.63 & $63 \mathrm{MOZ}$ & 7.02 & 40.31 & 98 UGA & 8.68 & 30.45 \\
\hline $29 \mathrm{ESP}$ & 3.41 & 33.30 & 64 MRT & 11.16 & 84.08 & 99 URY & 5.25 & 36.18 \\
\hline 30 ETH & 5.32 & 24.16 & 65 MUS & 7.26 & 103.22 & 100 USA & 2.35 & 16.05 \\
\hline $31 \mathrm{FIN}$ & 3.52 & 53.50 & $66 \mathrm{MWI}$ & 7.37 & 59.56 & $101 \mathrm{VEN}$ & 5.69 & 46.69 \\
\hline 32 FRA & 2.22 & 38.06 & $67 \mathrm{MYS}$ & 3.96 & 110.73 & $102 \mathrm{ZAF}$ & 3.15 & 50.01 \\
\hline $33 \mathrm{GAB}$ & 9.48 & 98.05 & 68 NAM & 7.59 & 91.34 & 103 ZAR & 8.51 & 39.27 \\
\hline 34 GBR & 2.12 & 49.96 & 69 NER & 8.49 & 39.26 & $104 \mathrm{ZMB}$ & 6.42 & 80.51 \\
\hline 35 GHA & 5.23 & 37.91 & 70 NGA & 9.90 & 44.35 & $105 \mathrm{ZWE}$ & 6.35 & 52.30 \\
\hline
\end{tabular}

Note: $\sigma_{G D P}$ is the standard deviation of the GDP growth rate, and open is the average openness (exports plus imports) as a fraction of GDP. Both statistics are computed over 1960-1997. 